\title{
$\beta-X$ vs. $\beta$-H Elimination. Selection Rules for Chemoselectivity Enabled by Mechanistic Studies
}

\author{
Authors: Michael K. Bogdos, ${ }^{1}$ Olivera Stepanović, ${ }^{1}$ Alessandro Bismuto, ${ }^{1}$ Mauro G. Luraschi, ${ }^{1}$ \\ Bill Morandi*1
}

${ }^{1}$ Laboratory of Organic Chemistry, Department of Chemistry and Applied Biosciences, ETH Zürich, Zürich, Switzerland

${ }^{*}$ Corresponding author. Email: bill.morandi@org.chem.ethz.ch

\section{Abstract:}

Alkylpalladium complexes are important intermediates in several industrially relevant catalytic reactions such as the Mizoroki-Heck, alkyl $\mathrm{C}-\mathrm{H}$ activation and ethylene polymerisation. Beta-elimination - of either a hydride $(\beta-H)$ or a heteroatom $(\beta-X)$ - is the most common decomposition pathway for these intermediates; this can either promote the desired reaction as in the Mizoroki-Heck reaction, or it can hinder reaction progress as in ethylene/vinyl halide co-polymerisations. Despite the importance of these elimination processes, little mechanistic understanding exists with respect to the factors that control them. We present a systematic investigation of the factors governing the competition between $\beta-\mathrm{H}$ and $\beta-X$ in catalytically relevant alkylpalladium complexes. These results enabled us to derive selection rules which dictate ligand choice to control selectivity for either elimination. This knowledge may allow chemists to manipulate betaeliminations in the design of chemoselective catalytic reactions for a wide range of applications.

\section{Introduction:}

The discovery and study of organometallic species have spurred the development of synthetic methods that have had a transformative impact on society, from the preparation of essential medicines to modern materials. ${ }^{1,2}$ A broad family of essential catalytic reactions, including Ziegler-Natta polymerisation, Mizoroki-Heck cross coupling, and alkyl C-H activation rely on transition metal-alkyl intermediates. ${ }^{3}$ These complexes are notably unstable, as they are prone to decompose through rapid beta-elimination reactions of either a hydride $(\beta-\mathrm{H})$ or a heteroatom $(\beta-X)$, generating an alkene and a $\mathrm{M}-\mathrm{H}$ or $\mathrm{M}-\mathrm{X}$ bond, respectively. ${ }^{3}$ Depending on the desired synthetic outcome, these eliminations need to be either prevented or promoted, which makes understanding and predicting this behavior essential to the design of catalytic reactions, since they lead to chemically distinct products.

Beta-hydride elimination $(\beta-\mathrm{H})$ is the main decomposition pathway for transition metal-alkyl complexes, often hindering their use in cross-coupling reactions (Fig. 1a). ${ }^{1,3,4}$ It is also an integral part of catalytic cycles for many important reactions, including the Mizoroki-Heck reaction, which has been used in the synthesis of highly complex and clinically important molecules such as cethromycin (Fig. 1a) ${ }^{5-8}$ As such, it has been studied extensively, with many metals and organic substrates being examined. ${ }^{3,9}$ Betaheteroatom elimination $(\beta-X)$ is related to $\beta-\mathrm{H}$, is similarly ubiquitous, but generally less studied and understood. It is also a transition metal-alkyl decomposition pathway, with important implications in polymer chemistry, where it inhibits the co-polymerisation of ethylene and vinyl halides or vinyl ethers and their derivatives (Fig. 1a).$^{10-12}$ Many examples of stoichiometric $\beta$-X eliminations have been reported, involving metals such as $\mathrm{Ni}, \mathrm{Pd}, \mathrm{Co}, \mathrm{Rh}$ and others. ${ }^{13-19}$ This fundamental step has also been exploited in catalysis. Examples include Mizoroki-Heck-type reactions (Fig. 1a) and asymmetric catalysis by Paioti et al., as well as the work of Tran et al. which shows a wide variety of $X$ groups being eliminated in a synthetically relevant context (Fig. 1b). ${ }^{7,20-23}$

As both beta-elimination reactions proceed through metal-alkyl complexes, they will often be in direct competition, leading to chemically distinct alkene products; such competitions have thus far been optimised empirically and have been comprehensively reviewed by Le Bras and Muzart. ${ }^{24}$ Despite this inherent competition in most systems, the ubiquity of both beta-elimination reactions, and the potential for controlling reactivity to produce chemodivergent outcomes, there is a paucity of systematic studies examining the 
factors controlling their competition. Such studies would ideally reveal general mechanistic trends, offer indepth understanding and predictive power for reaction design. To the best of our knowledge, only two examples studying such competitions exist, by Zhu and Zhang et al. respectively (Fig. 1b). ${ }^{25,26}$ These studies are limited to a narrow set of parameters (few $X$ groups, no ligands) and offer no general guidelines for reaction control. A thorough investigation of the $\beta-\mathrm{H} / \beta-\mathrm{X}$ competition would provide fundamental understanding and insight into how to control it, thereby increasing chemists' ability to design chemoselective catalytic reactions. Such findings would have wide impact, since transition metal-alkyl intermediates are of increasing importance, as saturated species are critical in the development of both materials science and medicinal chemistry. ${ }^{27-29}$

We report mechanistic investigations into the $\beta-X / \beta-H$ competition in phosphine-ligated palladium-alkyl complexes. We were able to understand the origin of the observed selectivity and to derive selection rules for diverting the intermediates selectively down either pathway. Such information may aid chemists in manipulating beta-eliminations in the design of chemoselective catalytic transformations.

\section{Results and Discussion:}

For our investigation we selected $\mathrm{Pd}$ as the metal of interest and monophosphines as the ligands, given that this combination represents one of the most used classes of catalyst in synthetically important reactions such as the Suzuki-Miyaura, Mizoroki-Heck, Negishi, Tsuji-Trost and Kumada-Corriu. ${ }^{30}$ As transition metal-alkyl complexes are quite unstable, we generated them in situ through oxidative addition of benzyl bromides, which bear the $\mathrm{X}$ group of interest at the homobenzylic position (Fig. 1c).
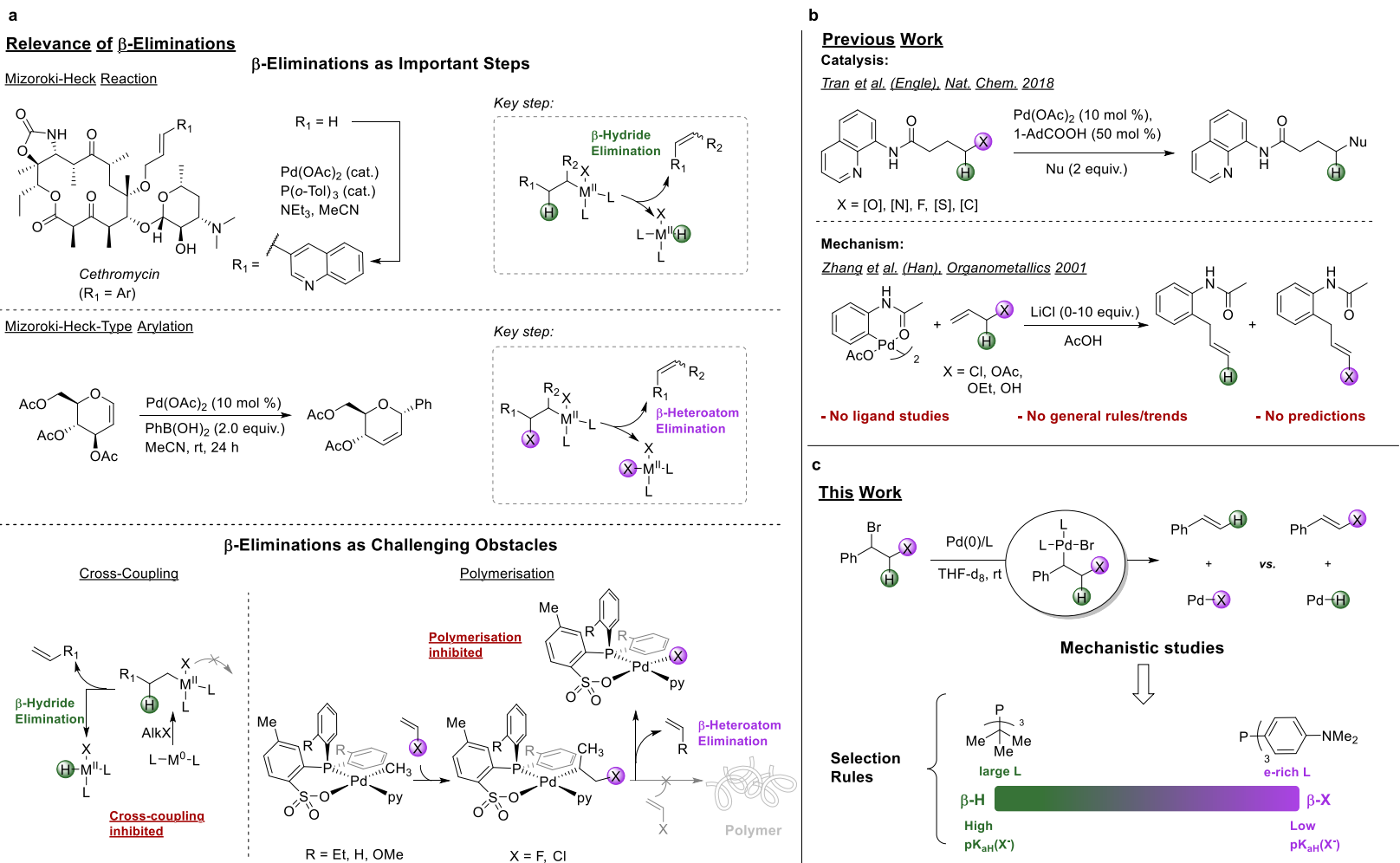

-Eliminations as Challenging Obstacles

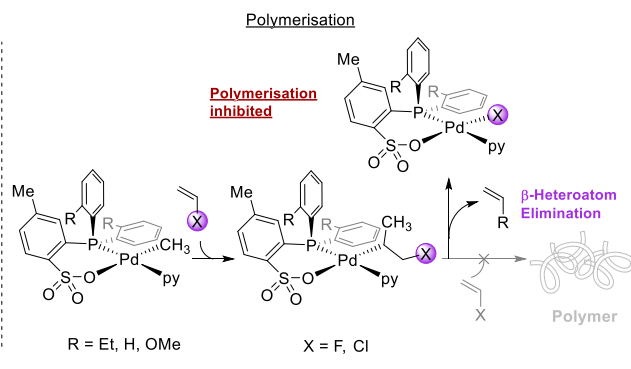

Fig. 1. Background and description of current work. (a) Importance of both $\beta-\mathrm{H}$ and $\beta-X$ in the context of transition-metal catalysed reactions and some challenges which beta-eliminations pose in cross-coupling of alkyl electrophiles and in the copolymerisation of vinyl halides with ethylene. (b) Previous work involving catalytic Pd-assisted $\beta-X$ and their competition with $\beta-\mathrm{H}$ in stoichiometric reactions (Zhang). (c) The work described in this report, assessing the relative preference for $\beta-\mathrm{X}$ or $\beta-\mathrm{H}$ elimination reactions in $\mathrm{Pd}$-alkyl monodentate phosphine complexes.

We prepared several substrates bearing various synthetically relevant $X$ groups; these include halides, phosphate, sulfonate and carboxylate esters (Fig. 2a). To gain insight on the kinetics of the competition, we monitored reaction progress over time using ${ }^{1} \mathrm{H}$ NMR. The organic products of the reactions serve as convenient reporters for the reaction selectivity. We initiated our studies using $\mathrm{Pd}\left(\mathrm{P}^{\mathrm{t}} \mathrm{Bu}_{3}\right)_{2}$ as the model $\mathrm{Pd}$ source, as it is a well-defined, highly reactive, and commercially available complex, which has been used 
as a catalyst in numerous transformations. ${ }^{31}$ Upon reaction with our substrates it gave rise to fast oxidative addition, followed by $\beta-\mathrm{H}$ and/or $\beta-\mathrm{X}$ elimination, all at room temperature.

The experimentally obtained selectivity was plotted against the aqueous $\mathrm{pK}_{\mathrm{a}}$ of the conjugate acid ( $\mathrm{pK}_{\mathrm{aH}}$ ) of the $X$ group being examined, in analogy to classic physical organic chemistry analyses (Fig. $2 b$ ). ${ }^{32}$ The $y$ axis is a scale which represents the selectivity of the reaction; 1 represents complete $\beta-X$ selectivity, -1 complete $\beta-\mathrm{H}$ selectivity, and 0 a 1:1 mixture of the two products (see SI section S3.1). The obtained graph shows a sigmoidal relationship between the two variables, with the function crossing the $x$ axis at a pK $\mathrm{K}_{\mathrm{aH}}$ of approximately -2 (Fig. 2b). The data was fit with a logistical regression function and the confidence intervals for both fit (dark grey) and prediction (light grey) are shown (see SI section S3.3). Based on the observed relationship between $\mathrm{pK}_{\mathrm{aH}}$ and selectivity, we conclude that $\mathrm{Pd}$-assisted $\beta-X$ eliminations are promoted by better leaving groups (see SI section S3.2 and S4.3). Next, we examined the case of fluoride ( $\mathrm{pK}_{\mathrm{aH}} \sim 3$ ) elimination, as it is a synthetically important example, ${ }^{33-35}$ since $\beta-F$ elimination is common in methods involving $\beta-X^{21,23,36,37}$ and is difficult to circumvent. ${ }^{38}$ Our model predicts a ratio of $45: 1$ favouring $\beta-\mathrm{H}$; indeed, an experimental ratio of $>50: 1$ in favour of $\beta-\mathrm{H}$ was obtained, illustrating the predictive capability of the selectivity/pK $\mathrm{K}_{\mathrm{aH}}$ relationship (Fig. $2 \mathrm{c}$ ).

Having validated our approach and observed a clear trend for a commonly used phosphine-Pd system, we next sought to probe whether the nature of the ligand could influence the overall selectivity of the process, as is the case for many other reactions involving Pd. ${ }^{39,40}$ Next, we focused on the most common combination of $\mathrm{Pd}$ and phosphine in the literature, namely $\mathrm{Pd} / \mathrm{PPh}_{3}{ }^{41}$ As with $\mathrm{Pd}\left(\mathrm{P}^{\mathrm{t}} \mathrm{Bu}_{3}\right)_{2}$, the relationship between selectivity and $\mathrm{pK}_{\mathrm{aH}}$ of $\mathrm{X}$ displayed a sigmoidal relationship, with the same equation describing the function of best fit (Fig. 2d), further validating our previous findings. The data show that the choice of phosphine strongly affects the preference of $\mathrm{Pd}$-assisted $\beta$-X eliminations, with a difference of nearly 7 units in the $\mathrm{pK}_{\mathrm{aH}}$ of $\mathrm{X}$ that results in 1:1 competition. Interestingly, despite the preference of $\mathrm{PPh}_{3}$ to favour $\beta-\mathrm{X}$, the overall trend remains similar and a clear correlation with the $\mathrm{pK}_{\mathrm{aH}}$ of the leaving $\mathrm{X}$ group is still observed.

a

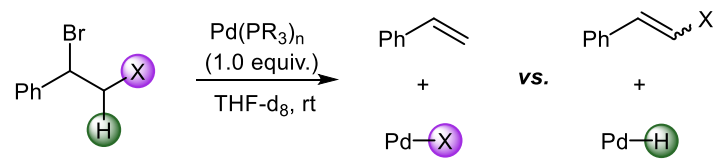

$\underline{\underline{X} \text { groups: }}$

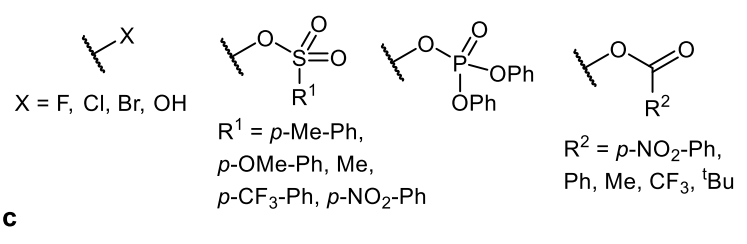

Prediction from model:

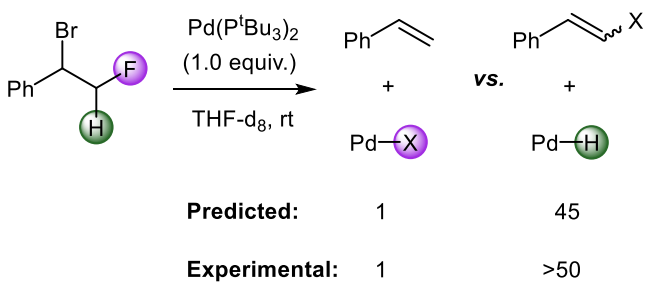

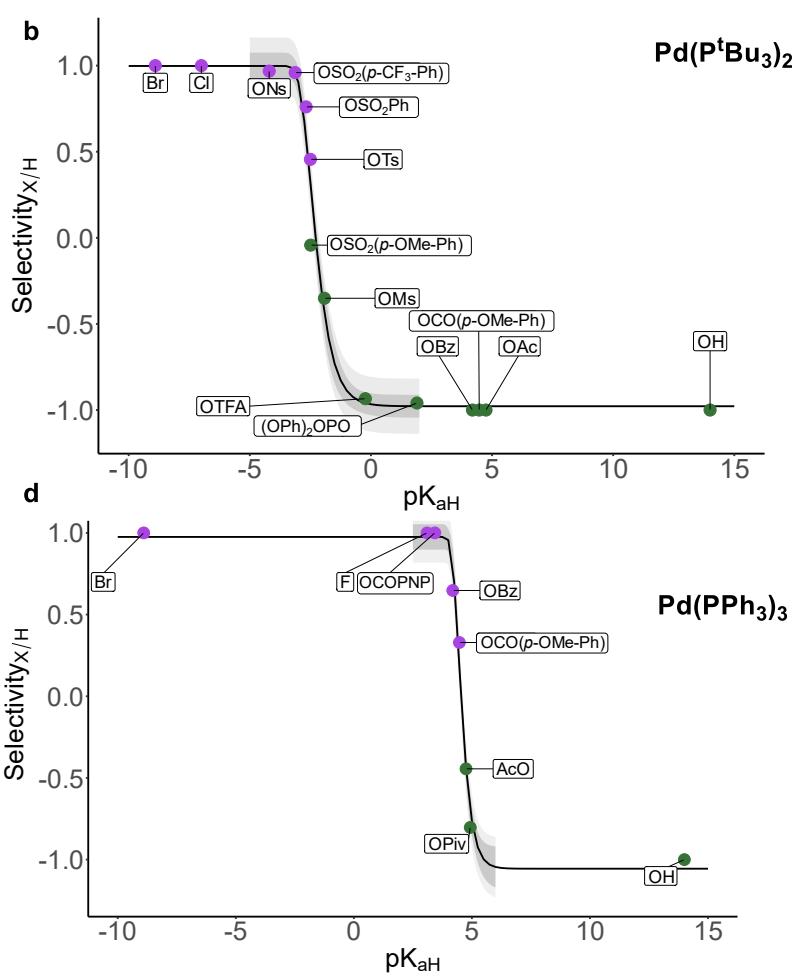

Fig. 2. Investigation of the influence of $X$ group. (a) Reactions carried out to assess the effect of $X$ group identity in the $\beta$-X vs. $\beta-H$ competition

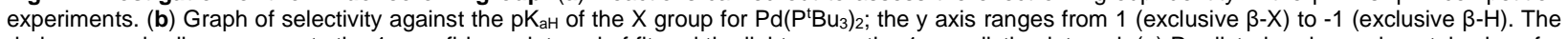
darker grey shading represents the $1 \sigma$ confidence interval of fit and the lighter grey the $1 \sigma$ prediction interval. (c) Predicted and experimental values for the fluorine bearing substrate. (d) Graph of selectivity against the $\mathrm{pK}_{\mathrm{aH}}$ of the $\mathrm{X}$ group for $\mathrm{Pd}\left(\mathrm{PPh}_{3}\right)_{3}$; confidence intervals depicted as in (b).

To understand the origin of the strong ligand effect, we decided to systematically probe the role of the phosphine ligand on the reaction. Since $\mathrm{PPh}_{3}$ and $\mathrm{P}^{\mathrm{t} B u_{3}}$ differ in both sterics and electronics, we decided to first interrogate the effect of varying the electronics, as this is easily achieved without affecting sterics by 
using various para-substituted triarylphosphines. We selected the substrate with $X=O A c$ as the model substrate for these studies, since it displayed competition near 1:1 in our studies with $\mathrm{PPh}_{3}$.

We reacted the chosen substrate with isolated homoleptic $\mathrm{Pd}(0)$ complexes ligated with para-substituted triarylphosphines bearing electron-withdrawing $(\mathrm{Cl})$ and electron-donating (OMe, $\mathrm{NMe}_{2}$ ) groups (Fig. 3a). By plotting the obtained selectivity against the Tolman electronic parameter (TEP) for each ligand, ${ }^{42,43}$ we observe that $\beta-X$ is promoted by more electron rich ligands.

Despite having very similar electronic character (TEP $2054 \mathrm{~cm}^{-1}$ and $2056 \mathrm{~cm}^{-1}$ respectively), $\mathrm{P}\left(p-\mathrm{NMe}_{2}-\right.$ $\mathrm{Ph})_{3}$ and $\mathrm{P}^{\mathrm{t} B u_{3}}$ lead to opposite outcomes, suggesting an overriding influence of sterics (Fig. 3b). It is known that $\mathrm{Pd}\left(\mathrm{P}^{\mathrm{t}} \mathrm{Bu}_{3}\right)_{2}$ forms monophosphine $\mathrm{T}$-shaped $\mathrm{Pd}$-aryl complexes after oxidative addition, as a result of the large steric demand of the $\mathrm{P}^{\mathrm{t} B u_{3}}$ ligand. ${ }^{44-47}$ In contrast, the less sterically demanding aryl phosphine $\mathrm{Pd}(0)$ complexes are known to generally form diphosphine square planar $\mathrm{Pd}(\mathrm{II})$ complexes after oxidative addition of aryl or benzyl electrophiles. ${ }^{48}$ We hypothesised that this sterically controlled change in ligation state of the reactive intermediate could be the reason for the observed discrepancy. To experimentally confirm that the speciation change also occurs with benzyl electrophiles, we reacted $\mathrm{Pd}\left(\mathrm{P}^{\mathrm{t}} \mathrm{Bu}_{3}\right)_{2}$ with excess $\mathrm{BnBr}$ and characterised the product of the reaction by ${ }^{31} \mathrm{P}\left\{{ }^{1} \mathrm{H}\right\} \mathrm{NMR}$ and single crystal X-ray diffraction, confirming the presence of only one phosphine (Fig. 3b; see SI sections S2.2 and S6). We also performed in situ variable temperature NMR experiments, which showed the continued presence of $\mathrm{P}^{\mathrm{t} B \mathrm{Bu}_{3}}$ during the course of the reaction, providing additional evidence supporting the monophosphine intermediate hypothesis (see SI section S5.6).

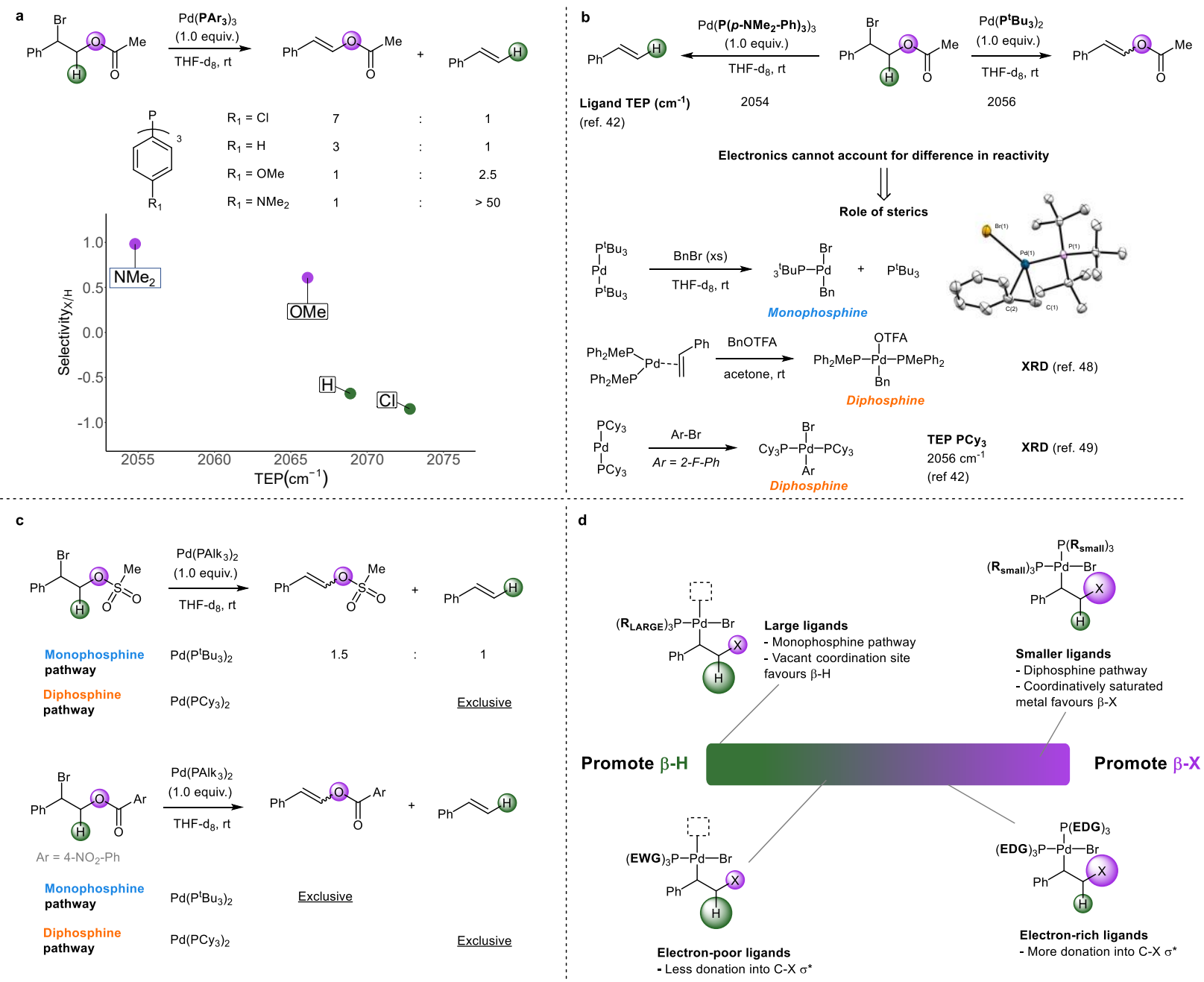

Fig. 3. Effect of phosphine ligand choice on reaction outcome. (a) Examination of the effect of electronics on the competition. The graph depicts the selectivity plotted against the TEP of the tested phosphines. (b) Divergent reactivity of two phosphines with similar TEP values. The product of oxidative 
addition of $\mathrm{BnBr}$ with $\mathrm{Pd}\left(\mathrm{P}^{\mathrm{t}} \mathrm{Bu}_{3}\right)_{2}$ was characterized by $\mathrm{XRD}$ and is shown; thermal ellipsoids are shown at $50 \%$ probability and hydrogen atoms are omitted for clarity. (c) Experiments comparing different substrates reacted with alkyl phosphine Pd complexes with similar electronics but different sterics. (d) Short summary of the derived selection rules from our investigations.

To further examine our hypothesis about the effect of the intermediate's ligation state on $\beta-X / \beta-H$ selectivity, we selected another trialkyl phosphine with a similar TEP to $\mathrm{P}^{\mathrm{t} B \mathrm{~B}_{3}}$ in order to evaluate its reactivity. In contrast to $\mathrm{P}^{\mathrm{t}} \mathrm{Bu}_{3}, \mathrm{PC}_{3}$ has been shown to form diphosphine ligated complexes and has the appropriate electronic profile (TEP $2056 \mathrm{~cm}^{-1}$, Fig. 3b). ${ }^{49-51}$ If the hypothesis holds, reaction of a substrate that displays $\beta-X / \beta-H$ competition with $\mathrm{P}^{\mathrm{t} B \mathrm{~B}_{3}}$ should give exclusive $\beta-X$ with $\mathrm{PC} \mathrm{y}_{3}$. Reacting the appropriate substrate $(X$ $=\mathrm{OMs})$ with both $\mathrm{Pd}\left(\mathrm{P}^{\mathrm{t} B \mathrm{Bu}_{3}}\right)_{2}$ and $\mathrm{Pd}\left(\mathrm{PC}_{3}\right)_{2}$, we obtained $\beta-\mathrm{X} / \beta-\mathrm{H}$ competition and exclusive $\beta-\mathrm{X}$ products respectively, in line with the ligation state hypothesis (Fig. $3 \mathrm{C}$ ). This is further corroborated by reaction with the substrate with $\mathrm{X}=\mathrm{OCOAr}\left(\mathrm{Ar}=4-\mathrm{NO}_{2}-\mathrm{Ph}\right)$, where $\mathrm{Pd}\left(\mathrm{P}^{\mathrm{t}} \mathrm{Bu}_{3}\right)_{2}$ gives rise to exclusive $\beta-\mathrm{H}$ and $\mathrm{Pd}\left(\mathrm{PC} y_{3}\right)_{2}$ to exclusive $\beta-X$. It should be noted that the ligation state of transition metal-phosphine species has been recently shown to have a strong influence on reactivity by Newman-Stonebreaker et al, further supporting our hypothesis. ${ }^{52}$

To rationalise the striking difference in elimination preference, we undertook experiments using stereochemical probes to investigate the stereochemical requirements of $\beta$-X (see SI section S5.5). By using the two diastereomers of 1,2-dibromopropylbenzene, we were able to deduce that both syn- and antieliminations are permissible pathways for $\beta-X$, the latter being preferred; these findings agree with the results reported by Sugita et al. ${ }^{53}$

Based on the above evidence, we propose that sterically demanding ligands promote the formation of threecoordinate T-shaped intermediates, which accelerate the stereospecific syn- $\beta-\mathrm{H}$ elimination by virtue of their vacant coordination site. The relative preference for $\beta-X$ is not altered by the vacant coordination site, due to both syn- and anti-eliminations being accessible. This leads to a relative increase in $\beta-\mathrm{H}$, allowing selective $\beta-\mathrm{H}$ in the presence of $\mathrm{X}$ groups that are eliminated in reactions where diphosphine intermediates are at play (e.g. $\mathrm{X}=\mathrm{F})$.

Overall, these investigations have led us to derive someselection rules for the $\beta-X / \beta-H$ competition (Fig $3 d$ ). Electron-rich ligands promote $\beta-X$, possibly due to an increased electron density which can be donated into the $\mathrm{C}-\mathrm{X} \sigma^{*}$. Ligands that are small enough to permit the formation of diphosphine- $\mathrm{Pd}(\mathrm{II})$ intermediates also promote $\beta-X$ relative to $\beta-H$. Conversely, electron-poor ligands promote $\beta-H$ relative to $\beta-X$, as do large ligands which promote the formation of monophosphine-Pd(II) intermediates.

\section{Conclusion:}

In summary, by studying the stoichiometric reactivity of $\mathrm{Pd}$ complexes bearing monodentate phosphine ligands, we have uncovered the factors governing the competition between $\beta-X$ and $\beta-H$. The first observation we made was that the ability to perform $\beta-X$ is contingent on the leaving group ability of the $X$ group; lower $\mathrm{pK} \mathrm{K}_{\mathrm{aH}}$ of $\mathrm{X}$ enables $\beta-X$. More electron-rich ligands promote $\beta-X$, while $\beta-\mathrm{H}$ is promoted by more electron-poor ligands, though the influence of electronics is much smaller than that of sterics. The size of the ligand influences the reaction by controlling the ligation state of the intermediate. A monophosphine and a diphosphine pathway operate; the former is promoted by large ligands and strongly favours $\beta-\mathrm{H}$ due to the presence of a free coordination site on $\mathrm{Pd}$. This allows selective $\beta-\mathrm{H}$ elimination in the presence of $X$ groups with a $\mathrm{pK}_{\mathrm{aH}}>0$ at room temperature. The diphosphine pathway is favoured by smaller ligands and appears to preferentially eliminate $\mathrm{X}$ groups with an approximate $\mathrm{pK}_{\mathrm{aH}}<6$ at room temperature.

We believe that this work will serve as a roadmap for further study of this competition and for guiding catalyst selection for the development of new methods incorporating $\beta-X$ and $\beta-H$ elementary steps. Further investigations into the role of Lewis acids, salt additives, bases, the choice of metal, the denticity and class of ligand and other factors are still necessary to fully appreciate the opportunities available for control over the selectivity.

\section{References and Notes}

1. Crabtree, R. H. The organometallic chemistry of the transition metals (Wiley 4th Edition) (2005).

2. Prashad, M. Palladium-Catalyzed Heck Arylations in the Synthesis of Active Pharmaceutical Ingredients. Topics in Organometallic Chemistry 6, 181-203 (2004).

3. Hartwig, J. F. Organotransition Metal Chemistry: From Bonding to Catalysis. (2010). 
4. Rudolph, A. \& Lautens, M. Secondary Alkyl Halides in Transition-Metal-Catalyzed Cross-Coupling Reactions. Angewandte Chemie - International Edition 48, 2656-2670 (2009).

5. de Meijere, A. \& Meyer, F. E. Fine Feathers Make Fine Birds: The Heck Reaction in Modern Garb. Angewandte Chemie International Edition in English 33, 2379-2411 (1995).

6. Lu, X. Control of the $\beta$-Hydride Elimination Making Palladium-Catalyzed Coupling Reactions More Diversified. Topics in Catalysis 35, 73-86 (2005).

7. Ramnauth, J., Poulin, O., Rakhit, S. \& Maddaford, S. P. Palladium(II) Acetate Catalyzed Stereoselective C-Glycosidation of Peracetylated Glycals with Arylboronic Acids. Organic Letters 3, 2013-2014 (2001).

8. Or, Y. S. et al. Design, Synthesis, and Antimicrobial Activity of 6-O-Substituted Ketolides Active Against Resistant Respiratory Tract Pathogens. Journal of Medicinal Chemistry 43, 1045-1049 (2000).

9. Chirik, P. J. \& Bercaw, J. E. Cyclopentadienyl and Olefin Substituent Effects on Insertion and $\beta$ Hydrogen Elimination with Group 4 Metallocenes. Kinetics, Mechanism, and Thermodynamics for Zirconocene and Hafnocene Alkyl Hydride Derivatives. Organometallics 24, 5407-5423 (2005).

10. Wada, S. \& Jordan, R. F. Olefin Insertion into a Pd-F Bond: Catalyst Reactivation Following $\beta-F$ Elimination in Ethylene/Vinyl Fluoride Copolymerization. Angewandte Chemie 129, 1846-1850 (2017).

11. Stockland, R. A. \& Jordan, R. F. Reaction of Vinyl Chloride with a Prototypical Metallocene Catalyst: Stoichiometric Insertion and $\beta-\mathrm{Cl}$ Elimination Reactions with rac-(EBI)ZrMe+ and Catalytic Dechlorination/Oligomerization to Oligopropylene by rac- (EBI)ZrMe $2 / M A O$. Journal of the American Chemical Society 122, 6315-6316 (2000).

12. Luckham, S. L. J. \& Nozaki, K. Toward the Copolymerization of Propylene with Polar Comonomers. Accounts of Chemical Research 54, 344-355 (2021).

13. Carpenter, A. E. et al. Direct Observation of $\beta$-chloride Elimination from an Isolable $\beta$-Chloroalkyl Complex of Square-Planar Nickel. Journal of the American Chemical Society 136, 15481-15484 (2014).

14. Munro-Leighton, C., Adduci, L. L., Becker, J. J. \& Gagné, M. R. Oxidative addition of secondary C$X$ bonds to palladium(0): A beneficial anomeric acceleration. Organometallics 30, 2646-2649 (2011).

15. Yeung, S. K. \& Chan, K. S. 1,2-Rearrangements of $\beta$-Nitrogen-Substituted (Porphyrinato)rhodium(III) Ethyls. Organometallics 24, 2561-2563 (2005).

16. Galinkina, J. et al. Synthesis, Characterization, and Reactivity of (Fluoroalkyl)- and (Fluorocycloalkyl)cobaloximes: Molecular Structure of a (2-Fluorocyclohexyl)cobaloxime Complex and Hindered Rotation of 2-Fluorocycloalkyl Ligands. Organometallics 22, 4873-4884 (2003).

17. Huang, D., Renkema, K. B. \& Caulton, K. G. Cleavage of F-C(sp²) bonds by $\mathrm{MHR}(\mathrm{CO})(\mathrm{PtBu} 2 \mathrm{Me})_{2}$ $\left(\mathrm{M}=\mathrm{Os}\right.$ and $\mathrm{Ru} ; \mathrm{R}=\mathrm{H}, \mathrm{CH}_{3}$ or Aryl): Product dependence on $\mathrm{M}$ and $\mathrm{R}$. Polyhedron 25, 459-468 (2006).

18. Braun, T. \& Hughes, R. P. Organometallic Fluorine Chemistry. Organometallic Fluorine Chemistry (2015).

19. Strazisar, S. A. \& Wolczanski, P. T. Insertion of $\mathrm{H}_{2} \mathrm{C}=\mathrm{CHX}\left(\mathrm{X}=\mathrm{F}, \mathrm{Cl}, \mathrm{Br}\right.$, OiPr) into $\left({ }^{(} \mathrm{Bu} \mathrm{S}_{3} \mathrm{SiO}_{3}\right)_{3} \mathrm{TaH} \mathrm{H}_{2}$ and $\beta$-X-Elimination from $\left(\mathrm{tBu}_{3} \mathrm{SiO}\right)_{3} \mathrm{HTaCH}_{2} \mathrm{CH}_{2} \mathrm{X}(\mathrm{X}=\mathrm{OR})$ : Relevance to Ziegler-Natta Copolymerizations. Journal of the American Chemical Society 123, 4728-4740 (2001).

20. Tran, V. T., Gurak, J. A., Yang, K. S. \& Engle, K. M. Activation of diverse carbon-heteroatom and carbon-carbon bonds via palladium(II)-catalysed $\beta$-X elimination. Nature Chemistry 10, 11261133 (2018).

21. Paioti, P. H. S. et al. Catalytic Enantioselective Boryl and Silyl Substitution with Trifluoromethyl Alkenes: Scope, Utility, and Mechanistic Nuances of Cu-F $\beta$-Elimination. Journal of the American Chemical Society 141, 19917-19934 (2019).

22. Vela, J. et al. Synthesis and Reactivity of Low-Coordinate Iron(II) Fluoride Complexes and Their Use in the Catalytic Hydrodefluorination of Fluorocarbons. Journal of the American Chemical Society 127, 7857-7870 (2005).

23. Butcher, T. W., Yang, J. L. \& Hartwig, J. F. Copper-Catalyzed Defluorinative Borylation and Silylation of gem-Difluoroallyl Groups. Organic Letters 22, (2020). 
25. Zhang, Z., Lu, X., Xu, Z., Zhang, Q. \& Han, X. Role of Halide ions in Divalent Palladium-Mediated Reactions: Competition between $\beta$-Heteroatom Elimination and $\beta$-Hydride Elimination of a CarbonPalladium Bond. Organometallics 20, 3724-3728 (2001).

26. Zhu, G. \& Lu, X. Reactivity and Stereochemistry of $\beta$-Heteroatom Elimination. A Detailed Study through a Palladium-Catalyzed Cyclization Reaction Model. Organometallics 14, 4899-4904 (1995).

27. Lovering, F. Escape from Flatland 2: complexity and promiscuity. MedChemComm 4, 515-519 (2013).

28. Lovering, F., Bikker, J. \& Humblet, C. Escape from Flatland: Increasing Saturation as an Approach to Improving Clinical Success. Journal of Medicinal Chemistry 52, 6752-6756 (2009).

29. McGuinness, D. Alkene oligomerisation and polymerisation with metal-NHC based catalysts. Dalton Transactions 6915-6923 (2009).

30. Pignolet, L. H. \& Fackler, J. P. Jr. Modern Inorganic Chemistry - Homogeneous Catalysis with Metal Phosphine Complexes. (1983).

31. He, L. Y. Bis(tri-tert-butylphosphine)palladium(0) $\left[\mathrm{Pd}\left(\mathrm{t}-\mathrm{Bu}_{3} \mathrm{P}\right)_{2}\right]$. Synlett 26, 851-852 (2015).

32. Johnson, C. D. Linear Free Energy Relationships and the Reactivity-Selectivity Principle. Chemical Reviews 75, 755-765 (1963).

33. Purser, S., Moore, P. R., Swallow, S. \& Gouverneur, V. Fluorine in Medicinal Chemistry. Chemical Society Reviews 37, 320-330 (2008).

34. Gillis, E. P., Eastman, K. J., Hill, M. D., Donnelly, D. J. \& Meanwell, N. A. Applications of Fluorine in Medicinal Chemistry. Journal of Medicinal Chemistry 58, 8315-8359 (2015).

35. Hagmann, W. K. The Many Roles for Fluorine in Medicinal Chemistry. Journal of Medicinal Chemistry 51, 4359-4369 (2008).

36. Corberán, R., Mszar, N. W. \& Hoveyda, A. H. NHC-Cu-Catalyzed Enantioselective Hydroboration of Acyclic and Exocyclic 1,1-Disubstituted Aryl Alkenes. Angewandte Chemie 123, 7217-7220 (2011).

37. Fujita, T., Fuchibe, K. \& Ichikawa, J. Transition-Metal-Mediated and -Catalyzed C-F Bond Activation by Fluorine Elimination. Angewandte Chemie - International Edition 58, 390-402 (2019).

38. Yuan, K., Feoktistova, T., Cheong, P. H. Y. \& Altman, R. A. Arylation of gem-difluoroalkenes using a $\mathrm{Pd} / \mathrm{Cu}$ Co-catalytic system that avoids $\beta$-fluoride elimination. Chemical Science 12, 1363-1367 (2021).

39. Schoenebeck, F. \& Houk, K. N. Ligand-Controlled Regioselectivity in Palladium-Catalyzed Cross Coupling Reactions. Journal of the American Chemical Society 132, 2496-2497 (2010).

40. Yang, Y. \& Buchwald, S. L. Ligand-Controlled Palladium-Catalyzed Regiodivergent SuzukiMiyaura Cross-Coupling of Allylboronates and Aryl Halides. Journal of the American Chemical Society 135, 10642-10645 (2013).

41. Searching SciFinder for the formation of a biaryl from an aryl bromide returns 3.1 million results, 1.2 million of which employ tetrakis(triphenylphosphine) palladium (0) as the catalyst.

42. Fey, N. et al. Development of a Ligand Knowledge Base, Part 1: Computational Descriptors for

Phosphorus Donor Ligands. Chemistry - A European Journal 12, 291-302 (2005).

43. Tolman, C. A. Steric Effects of Phosphorus Ligands in Organometallic Chemistry and Homogeneous Catalysis. Chemical Reviews 77, 313-348 (1977).

44. McMullin, C. L., Jover, J., Harvey, J. N. \& Fey, N. Accurate modelling of $\mathrm{Pd}(0)+\operatorname{PhX}$ oxidative addition kinetics. Dalton Transactions 39, 10833-10836 (2010).

45. Kim, D. et al. The site-selectivity and mechanism of Pd-catalyzed $\mathrm{C}\left(\mathrm{sp}^{2}\right)-\mathrm{H}$ arylation of simple arenes. Chemical Science 12, 363-373 (2021).

46. Stambuli, J. P., Incarvito, C. D., Bühl, M. \& Hartwig, J. F. Synthesis, Structure, Theoretical Studies, and Ligand Exchange Reactions of Monomeric, T-Shaped Arylpalladium(II) Halide Complexes with an Additional, Weak Agostic Interaction. Journal of the American Chemical Society 126, 1184-1194 (2004).

47. Tan, Y. \& Hartwig, J. F. Assessment of the Intermediacy of Arylpalladium Carboxylate Complexes in the Direct Arylation of Benzene: Evidence for C-H Bond Cleavage by "Ligandless" Species. Journal of the American Chemical Society 133, 3308-3311 (2011).

48. Narahashi, H., Shimizu, I. \& Yamamoto, A. Synthesis of benzylpalladium complexes through C-O bond cleavage of benzylic carboxylates: Development of a novel palladium-catalyzed benzylation of olefins. Journal of Organometallic Chemistry 693, 283-296 (2008). 
49. Larini, P. et al. On the Mechanism of the Palladium-Catalyzed $\beta$-Arylation of Ester Enolates. Chemistry - A European Journal 18, 1932-1944 (2012).

50. de Gombert, A., McKay, A. I., Davis, C. J., Wheelhouse, K. M. \& Willis, M. C. Mechanistic Studies of the Palladium-Catalyzed Desulfinative Cross-Coupling of Aryl Bromides and (Hetero)Aryl Sulfinate Salts. Journal of the American Chemical Society 142, 3564-3576 (2020).

51. Lee, W., Shin, C., Park, S. E. \& Joo, J. M. Regio- And Stereoselective Synthesis of ThiazoleContaining Triarylethylenes by Hydroarylation of Alkynes. Journal of Organic Chemistry 84, 12913-12924 (2019).

52. Newman-Stonebraker, S. H. et al. Univariate classification of phosphine ligation state and reactivity in cross-coupling catalysis. Science 308, 301-308 (2021).

53. Sugita, T., Shiraiwa, Y., Hasegawa, M. \& Ichikawa, K. Elimination Reactions of Halohydrin Derivatives with a Palladium (0) Complex. Bulletin of the Chemical Society of Japan 52, 36923631 (1979).

Acknowledgments: The authors would like to acknowledge Dr. Ori Green for helpful discussions during the development of the work. We also acknowledge Sven Roediger and Lukas Schlemper for chemicals. The NMR service and SMoCC service of the ETHZ are graciously acknowledged for their help in VT-NMR and XRD experiments respectively. The whole Morandi group is acknowledged for discussions on the project during group meetings and for critically proofreading and providing feedback on this manuscript.

Funding: The authors thank ETH Zürich for funding.

Author contributions: MKB conceived the project. All authors contributed to the design of experiments. MKB, OS, AB and MGL performed all experiments. BM supervised the research. All authors contributed to the writing and editing of the manuscript and supplementary information.

Competing interests: Authors declare that they have no competing interests.

Data and materials availability: All experimental data are available in the main text or the supplementary materials. 